\title{
Dynorphin A, kappa opioid receptors and the antinociceptive efficacy of asimadoline in streptozotocin-induced diabetic rats
}

\author{
C. G. Jolivalt • Y. Jiang • J. D. Freshwater • \\ G. D. Bartoszyk • N. A. Calcutt
}

Received: 2 December 2005 / Accepted: 17 July 2006 / Published online: 19 August 2006

(C) Springer-Verlag 2006

\begin{abstract}
Aims/hypothesis We investigated spinal and peripheral kappa opioid systems in diabetic rats.

Materials and methods Dynorphin A, $N$-methyl-D-aspartate (NMDA) and kappa opioid receptor (KOR) were measured in spinal cord, dorsal root ganglia, peripheral nerves and foot skin of control and streptozotocin-induced diabetic rats by immunoassay and Western blotting. Behavioural assessments of paw tactile sensitivity and formalin-evoked hyperalgesia were performed in normal and diabetic rats before and after treatment with asimadoline.

Results Dynorphin A protein levels were significantly increased in peripheral nerves and footpad skin of diabetic rats. Dynorphin A exhibits both anti- and pro-nociceptive properties depending on activation of either KOR or NMDA receptors. Spinal protein levels of these receptors were not changed by diabetes, while KOR levels in the sciatic and peroneal nerves were significantly increased. Exploiting the presence and elevated levels of KOR in the periphery, we investigated the effect of the peripheral KOR agonist asimadoline on formalin-evoked hyperalgesia and tactile allodynia in diabetic rats. Both formalin-evoked hyperalgesia and tactile allodynia in diabetic rats were acutely ameliorated by asimadoline. To confirm that the effect of asimadoline was related to its property as KOR agonist, diabetic rats were pretreated with the selective
\end{abstract}

C. G. Jolivalt $(\bowtie) \cdot$ Y. Jiang $\cdot$ J. D. Freshwater $\cdot$ N. A. Calcutt Department of Pathology, University of California San Diego, 9500 Gilman Drive,

La Jolla, CA 92093-0612, USA

e-mail: cjolivalt@ucsd.edu

G. D. Bartoszyk

Preclinical R\&D, Merck,

64271 Darmstadt, Germany
KOR antagonist nor-binaltorphimine. Intraplantar norbinaltorphimine abolished the ability of asimadoline to alleviate tactile allodynia in diabetic rats. Systemic and intrathecal nor-binaltorphimine partially inhibited the effect of asimadoline against formalin-evoked hyperalgesia in diabetic rats.

Conclusions/interpretation Using selective peripheral KOR agonists to take advantage of elevated peripheral KOR expression may provide a novel therapeutic approach for painful diabetic neuropathy.

Keywords Allodynia $\cdot$ Asimadoline $\cdot$ Diabetes $\cdot$ Dynorphin A $\cdot$ Hyperalgesia $\cdot$ Kappa opioid receptor $\cdot$ NMDA receptor
Abbreviations
DRG dorsal root ganglia
KOR kappa opioid receptor
NMDA $\quad N$-methyl-D-aspartate
nor-BNI nor-binaltorphimine
STZ streptozotocin

\section{Introduction}

Neuropathy is the most common secondary complication associated with diabetes mellitus and has symptoms that range from loss of sensation to spontaneous or touchevoked pain. The cause of diabetic painful neuropathy is unclear and like other neuropathic pain conditions may be the result of various pathological events, including increased ectopic primary afferent input and anatomic or neurochemical changes to spinal and supraspinal sensory processing mechanisms. Diabetic rats show behavioural indices of abnormal sensory function such as tactile 
allodynia and hyperalgesia to chemical stimuli and have been widely used as models to investigate the aetiology of painful diabetic neuropathy and to screen the efficacy of potential therapeutic interventions [1].

Our previous studies suggested that amplification of spinal sensory processing mechanisms that could contribute to allodynia or hyperalgesia occurs in diabetic rats $[2,3]$, but the mechanistic details remain to be clarified. Many of the features of allodynia in diabetic rats resemble those seen in models of neuropathic pain induced by physical nerve injury [4], and while examining neurochemical parallels between these models, we became interested in the effects of diabetes on the spinal dynorphin system. Dynorphin is an endogenous opioid peptide, originally identified as a ligand for the kappa opioid receptor (KOR) and therefore with potential antinociceptive properties [5]. However, injection of dynorphin to the rat spinal cord causes motor dysfunction or longlasting allodynia $[6,7]$ indicating pronociceptive properties. Preprodynorphin mRNA and dynorphin protein content are also increased in rat spinal cord after peripheral nerve injury or inflammation [8-10] and these changes are accompanied by onset of tactile allodynia [11]. Although dynorphin is not required for the initiation of neuropathic pain, it is required for the maintenance of persistent neuropathic pain [12], and this may be related to direct or indirect activation of $N$ methyl-D-aspartate (NMDA) receptors [13, 14]. Dynorphin levels are increased in the brain of diabetic rodents [15], but the effects of diabetes on dynorphin or its receptors in the spinal cord and peripheral nervous system have not been examined and their potential contribution to painful diabetic neuropathy or alleviation of this condition has not been explored.

In light of the above observations, we investigated dynorphin A and its associated receptors in the spinal cord, dorsal root ganglia (DRG), peripheral nerves and footpad skin of diabetic rats. Our findings prompted us to subsequently explore the ability of asimadoline (EMD61753), a KOR agonist with restricted ability to cross the blood-brain-barrier [16], to alleviate tactile allodynia and formalin-evoked hyperalgesia in diabetic rats. Asimadoline has antinociceptive properties in a number of inflammatory pain models [16-19] and alleviated mechanical hyperalgesia after sciatic nerve ligation [20], but its potential efficacy against diabetes-induced neuropathic pain has not yet been reported.

\section{Materials and methods}

Animals

All studies were performed using adult female SpragueDawley rats (Harlan Industries, San Diego CA, USA).
Animals were housed two to three per cage with free access to food and water and maintained in a vivarium approved by the American Association for the Accreditation of Laboratory Animal Care. All animal studies were carried out according to protocols approved by the Institutional Animal Care and Use Committee of the University of California San Diego.

Drugs

Asimadoline (EMB61753) was supplied by Merck (Darmstadt, Germany). Gabapentin and nor-binaltorphimine (nor-BNI) were purchased from Sigma (St. Louis, MO, USA) and morphine sulfate from Merck (West Point, PA, USA).

Induction of diabetes

Insulin-deficient diabetes was induced following an overnight fast by a single i.p. injection of streptozotocin (STZ; Sigma) at $50 \mathrm{mg} / \mathrm{kg}$ dissolved in $0.9 \%$ sterile saline. Hyperglycaemia was confirmed using a strip-operated reflectance meter in a blood sample obtained by tail prick 4 days after STZ injection and in another sample collected at the conclusion of the study.

Immunohistochemistry

Eight weeks after onset of hyperglycaemia, diabetic and control rats were anaesthetised and perfused with $0.9 \%$ saline, followed by $4 \%$ paraformaldehyde in $0.1-\mathrm{mol} / 1 \mathrm{PBS}$. Immediately after perfusion, bilateral L4 and L5 DRG were dissected and post-fixed in 4\% paraformaldehyde, cryoprotected by immersion in $0.1-\mathrm{mol} / 1$ PBS containing $30 \%$ sucrose, embedded in optimum-cutting-temperature medium, and stored at $-20^{\circ} \mathrm{C}$ prior to cryostat sectioning $(7-\mu \mathrm{m}$ sections). Dynorphin A- or KOR-immunoreactivity was visualised by the $\mathrm{ABC}$ method using 3,3'-diaminobenzidine as the chromagen. After washing with $0.05-\mathrm{mol} / 1$ Tris buffer solution ( $\mathrm{pH}$ 7.6), the sections were blocked with avitin-biotin block solution (Dako Corporation, Carpinteria, CA, USA) and 10\% normal goat serum containing $0.3 \%$ Triton-X. Sections were then incubated overnight at $4^{\circ} \mathrm{C}$ with selective rabbit anti-dynorphin A (Abcam, Cambridge, MA, USA) (1/50), or KOR (Biosource, Camarillo, CA, USA) $(1 / 1,000)$ antibodies in a medium containing $5 \%$ normal goat serum and $0.3 \%$ Triton-X. Sections were then incubated with biotinylated goat antirabbit antibody (1/200: Vector Laboratories, Burlingame, CA, USA), followed by StreptABC complex/HRP (DakoCytomation, Carpinteria, CA, USA). The immunoreactive products were visualised with a 3,3'-diaminobenzidine substrate kit (Vector). To minimise variability in stain intensity, tissues from control and diabetic rats were stained side by side and evaluation of non-specific 
staining was performed by omission of the primary antibody. Sections were evaluated by light microscopy.

Tissue collection

Spinal cords were obtained by hydraulic extrusion after decapitation of anaesthetised rats. Portions of the lumbar enlargement were collected either into ice-cold homogenisation buffer (50-mmol/1 Tris-HCl, pH 7.4, 150-mmol/ $1 \mathrm{NaCl}, 1-\mathrm{mmol} / \mathrm{LDTA}, 0.5 \%$ Triton $\mathrm{X}$, protease inhibitor cocktail) or into PBS. The L4/L5 DRG, segments of the sciatic, tibial and peroneal nerves and the plantar footpad skin were homogenised in $200 \mu \mathrm{l}$ of either ice-cold homogenisation buffer $(50-\mathrm{mmol} / 1$ Tris- $\mathrm{HCl}, \mathrm{pH} 7.4,150$ $\mathrm{mmol} / 1 \mathrm{NaCl}, 1-\mathrm{mmol} / 1$ EDTA, $0.5 \%$ Triton $\mathrm{X}$, protease inhibitor cocktail) or PBS.

\section{Dynorphin A}

Dynorphin A levels were determined in PBS tissue homogenates using a commercial immunoassay kit (sensitivity: $0.1 \mathrm{ng} / \mathrm{ml}$, specificity: $100 \%$ dynorphin A 1-17; Phoenix Pharmaceuticals, Belmont, CA, USA). Peptide levels were calculated for each animal in ng dynorphin A per mg of tissue protein. To allow for inter-plate variations, values for individual animals were expressed relative to the group mean of the control rat samples on the same plate.

\section{Western blotting}

Tissue homogenates were centrifuged $(14,000 \times g)$ and aliquots of the clear extract boiled in Laemmli LDS sample buffer (Invitrogen, Carlsbad, CA, USA). Next, 3 to $6 \mu \mathrm{g}$ of total extract protein were separated on $12 \%$ SDS-PAGE Tris-glycine gels (Novex; Invitrogen, Carlsbad, CA, USA) and immunoblotted on nitrocellulose. Membranes were incubated with anti-KOR $(1 / 1,000)$, anti-NMDA-R1 (1/ 500; Chemicon International, Temecula, CA, USA) or antiactin antibodies (1/2,000; Sigma, St. Louis, MO, USA), followed by incubation with horseradish peroxidase-linked anti-rabbit secondary antibody $(1 / 10,000$; Santa Cruz Biotechnology, Santa Cruz, CA, USA) for anti-KOR or anti-mouse secondary antibody (1/10,000; Santa Cruz) for anti-NMDA-R1 and anti-actin antibodies. Blots were developed using an enhanced chemiluminescence westernblotting protocol (Amersham Pharmacia Biotech, Little Chalfont, UK). For sequential analysis of Western-blot membranes, previously bound antibodies were removed with stripping buffer $(0.2-\mathrm{mol} / 1$ glycine, $\mathrm{pH} 2.5,0.05 \%$ Tween 20). Quantification of immunoreactivity was performed by densitometric scanning using Quantity One software (BioRad, San Diego, CA, USA). For each animal, band intensities were normalised by calculating the ratio of the intensity of the band corresponding to KOR or NMDA$\mathrm{R} 1$ to the intensity of the band corresponding to actin. To allow grouping of samples run on different gels, actinnormalised densitometric measures of band intensity for each animal were then expressed as a percentage of the group mean of all samples from control rats present on the same gel.

Tactile response threshold

Tactile allodynia was assessed using von Frey filaments as described in detail elsewhere [4]. The cumulative response over the $4 \mathrm{~h}$ following drug delivery was presented as the AUC using the sum of the raw data points. For presentation purposes, group responses over time were transformed to percentage maximal effect (\%MPE) by designating the predrug value for each animal as $0 \%$ effect and thresholds of $15 \mathrm{~g}$ as $100 \%$ effect [21].

Formalin-evoked flinching

Rats were restrained manually and formalin $(50 \mu \mathrm{l}$ of $0.5 \%$ solution) injected sub-dermally into the hind paw dorsum. Rats were then placed in an observation chamber and flinching behaviours counted in 1-min blocks every $5 \mathrm{~min}$ for $1 \mathrm{~h}$ [22]. The sum of flinches was grouped to highlight specific phases of the test (phase $1=\min 1-2,5-6$ and 10 11 ; phase $2=$ remaining time points).

Intrathecal catheter implantation

nor-BNI was injected directly into the spinal cord via an indwelling intrathecal catheter implanted as described elsewhere [4].

Treatment

Rats were untreated for the first 4 weeks of diabetes. After confirmation of tactile allodynia, a single dose of asimadoline, morphine, gabapentin or vehicle $(0.9 \%$ normal saline) was delivered prior to measurement of tactile allodynia. In some studies, the selective KOR antagonist nor-BNI or saline vehicle were delivered $30 \mathrm{~min}$ prior to asimadoline $(15 \mathrm{mg} / \mathrm{kg}$ s.c.) or saline injection. Paw formalin injection and subsequent quantification of flinching behaviour were performed on separate animals. Asimadoline $(1,5$, or $15 \mathrm{mg} / \mathrm{kg}$ s.c.) was delivered $1 \mathrm{~h}$ prior to paw formalin injection and flinching was followed for a further hour after formalin injection.

\section{Statistical analysis}

Statistical analysis of parametric data was performed using the unpaired $t$-test to compare between control and diabetic 
groups. AUC was derived from non-parametric data and therefore between-group comparisons were made by the Kruskal-Wallis test with post hoc identification using Dunn's test. For the formalin test, statistical analysis of parametric data was performed using one-way ANOVA followed by the Dunnett post hoc test to compare all groups against untreated diabetic rats. Parametric and transformed non-parametric data are reported as group mean \pm SEM.

\section{Results}

Diabetes

Diabetic rats exhibited hyperglycaemia (blood sugar $>15 \mathrm{mmol} / \mathrm{l}) 4$ days after STZ injection and also immediately prior to behavioural testing. Levels were uniformly above the upper limit of detection of our meter $(22.2 \mathrm{mmol} / \mathrm{l})$.

\section{Dynorphin}

Dynorphin A protein levels (representative values given in $\mathrm{ng} / \mathrm{mg}$ protein for control vs diabetic) were significantly $(p<0.05)$ increased in the sciatic $(0.107 \pm 0.02$ vs $0.411 \pm 0.07)$, peroneal $(0.175 \pm 0.04$ vs $0.336 \pm 0.1)$ and tibial $(0.187 \pm 0.05$ vs $0.257 \pm 0.03)$ nerves and footpad skin $(1.269 \pm 0.39$ vs $3.919 \pm$ 1.37) of diabetic rats (Fig. 1). A similar trend was apparent in the spinal cord $(0.037 \pm 0.01$ vs $0.060 \pm 0.01)$ but not the DRG $(0.106 \pm 0.02$ vs $0.086 \pm 0.02)$. Dynorphin A-immunoreactivity was most apparent in the cytoplasm of sensory neuron cell bodies located in the DRG of both control and diabetic rats (Fig. 2). Immunostaining did not appear to be selective for any particular size of neuron or vary markedly in intensity between the two groups. Dynorphin A immunoreactivity was most pronounced in Schwann cells of the sciatic nerve of both control and diabetic rats where immunostained signet ring profiles of Schwann cell cytoplasm were evident (Fig. 2) and was confirmed by dynorphin A-immunoreactivity co-staining with the S-100 marker for myelinating cells (data not shown).
Fig. 1 Dynorphin A levels measured by enzyme immunoassay in spinal cord (a), dorsal root ganglia (b), sciatic nerve (c), peroneal nerve (d), tibial nerve (e), footpad skin (f). Data are group mean \pm SEM. $n=6-20$ per group. ${ }^{*} p<0.05, * * * p<0.001$ vs control by unpaired $t$-test
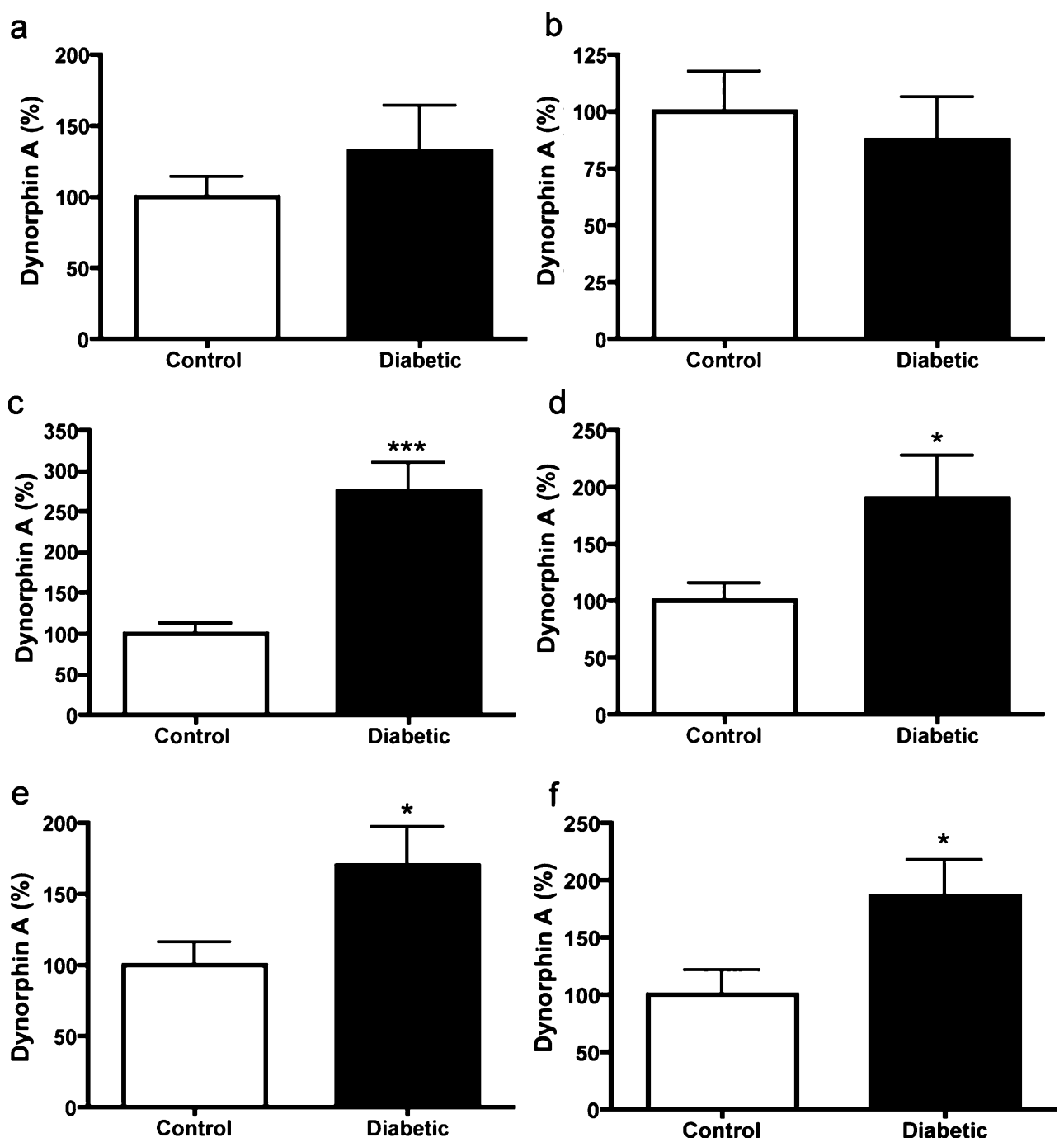
Fig. 2 Dynorphin A immunoreactivity in cytoplasm of DRG neurons $(\mathbf{a}, \mathbf{b})$ and in Schwann cells of sciatic nerve $(\mathbf{c}, \mathbf{d})$ from control (a, c) and diabetic (b, d) rats. Arrowhead, dynorphin A staining in cytoplasm of a DRG neuron; arrow, dynorphin A staining in Schwann cells of sciatic nerve, evident as distinctive signet ring profiles around axons. Bar $=40 \mu \mathrm{m}$. Inset (a), wide-field view of a DRG from a control rat immunostained for dynorphin A. Bar $=200 \mu \mathrm{m}$. Inset (b), specificity of immunostaining by omission of the primary antibody. Bar $=40 \mu \mathrm{m}$
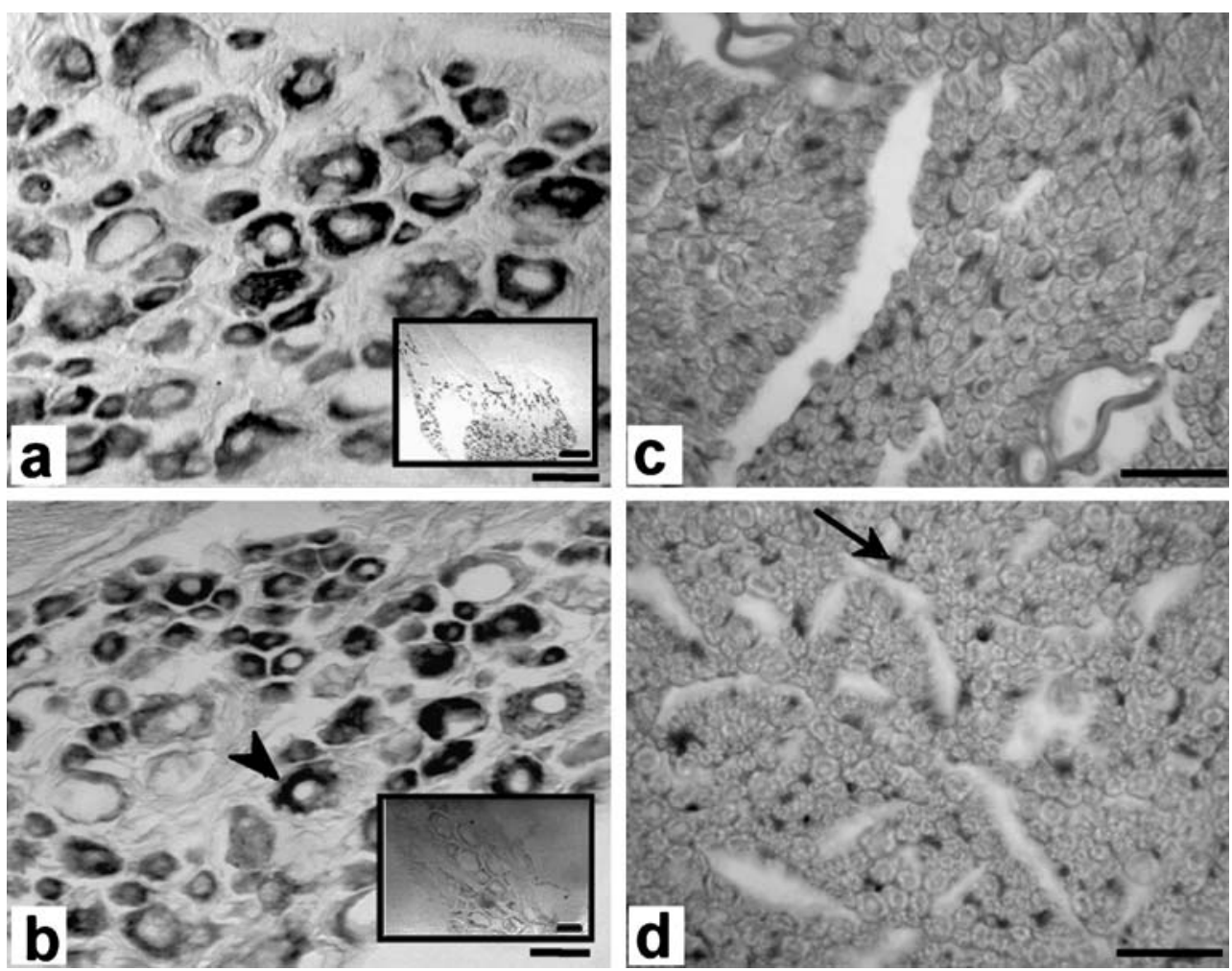

\section{Receptor proteins}

Quantification of KOR protein levels by Western blot indicated a significant increase in sciatic and peroneal nerve from diabetic rats $(p<0.01$ and $p<0.05$ vs control, respectively, Fig. 3) with a similar trend apparent in the DRG. KOR protein levels of footpad skin, tibial nerve and spinal cord were similar in both groups. KOR-immunoreactivity was present in DRG from both control and diabetic rats and was localised to satellite cells but not neurons (Fig. 4), as confirmed by KOR-immunoreactivity co-staining with immunoreactivity of the satellite cell marker glutamine synthetase and lack of co-staining with the neuronal marker NeuN (data not shown). In sciatic nerve, KOR immunostaining was most evident in signet ring profiles indicative of myelinating Schwann cells (Fig. 4), and was confirmed by co-staining with the S-100 marker for myelinating cells (data not shown). Levels of NMDA receptor subunit 1 protein were similar in control and diabetic rat spinal cord $(100.0 \pm 12.2 \%$ vs $89.1 \pm 13.4 \%, n=14-17)$ and were not detectable in sciatic and peroneal nerves of control and diabetic rats (data not shown).

\section{Tactile allodynia}

All diabetic rats showed marked allodynia, as defined by a $50 \%$ response threshold below $5 \mathrm{-g}$ force (cohort mean $\pm \mathrm{SEM}=2.49 \pm 0.13 \mathrm{~g}$; median=2.37 $\mathrm{g} ; n=40$ ), whereas control rats were generally unresponsive to light touch (group mean $\pm \mathrm{SEM}=11.71 \pm 1.53 \mathrm{~g}$; median=14.00 g; $n=8$ ). Systemic saline did not alter tactile response threshold of diabetic over the subsequent $4 \mathrm{~h}$ (Fig. 5), whereas systemic gabapentin alleviated tactile allodynia in diabetic rats with maximal efficacy occurring between 1 and $3 \mathrm{~h}$ after injection. Subcutaneous delivery of asimadoline alleviated tactile allodynia in a dose-dependent manner in diabetic rats with the highest dose $(15 \mathrm{mg} / \mathrm{kg})$ matching the time and efficacy profile of gabapentin (Fig. 5). Neither drug was associated with any overt changes in motor function or general physiology and behaviour of the animals.

To confirm that alleviation of tactile allodynia by asimadoline was mediated by the KOR, diabetic rats were pretreated with the selective antagonist nor-BNI $30 \mathrm{~min}$ prior to asimadoline injection. Intraperitoneal injection of $1 \mathrm{mg}$ of nor-BNI did not markedly alter the action of asimadoline $(15 \mathrm{mg} / \mathrm{kg}$ s.c.) beyond the first hour posttreatment but intraplantar injection of $100 \mu \mathrm{g}$ of nor-BNI (in $20-\mu \mathrm{l}$ saline) abolished the anti-allodynic effect of asimadoline for up to $4 \mathrm{~h}$ (Fig. 6). This was not due to either the vehicle or the injection itself, as $20 \mu \mathrm{l}$ of saline injected into the paw of diabetic rats did not alter the effect of asimadoline (Fig. 6).

Cumulative tactile responses over the 4-h test period are reported in Table 1. Asimadoline $(15 \mathrm{mg} / \mathrm{kg}$ s.c.) significantly alleviated allodynia of diabetic rats $(p<0.05$ vs saline) and this effect was abolished by intraplantar $(p<0.01)$ but not systemic nor-BNI. Tactile responses of control or diabetic rats were not affected by intraplantar 
Fig. 3 KOR protein levels measured by western blot in spinal cord (a), dorsal root ganglia (b), sciatic nerve (c), peroneal nerve (d), tibial nerve (e), footpad skin (f) of control and diabetic rats. Insert (c): Western blot of sciatic nerve for KOR. Data are group mean \pm SEM. $n=6-28$ per group. ${ }^{*} p<0.05$, $* * p<0.01$ vs control by unpaired $t$-test a

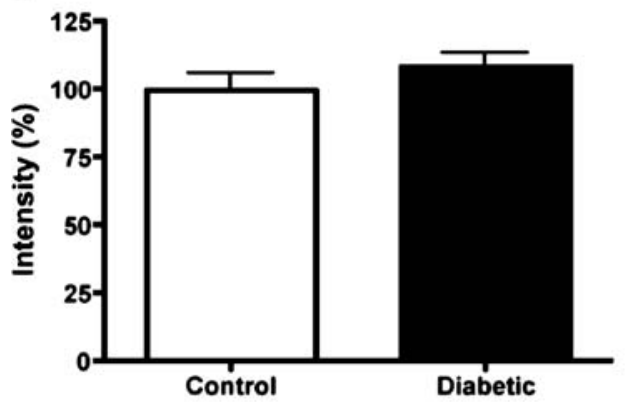

c

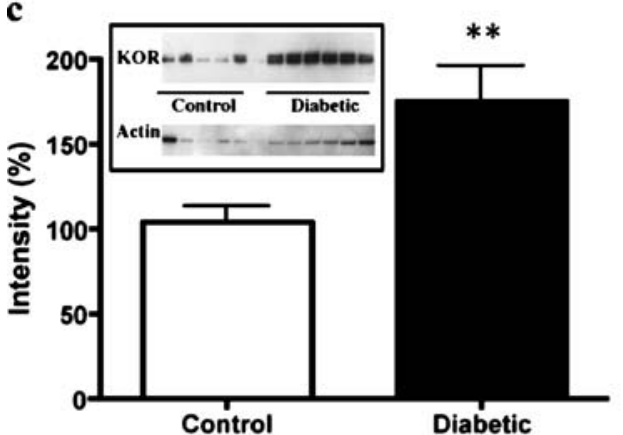

e

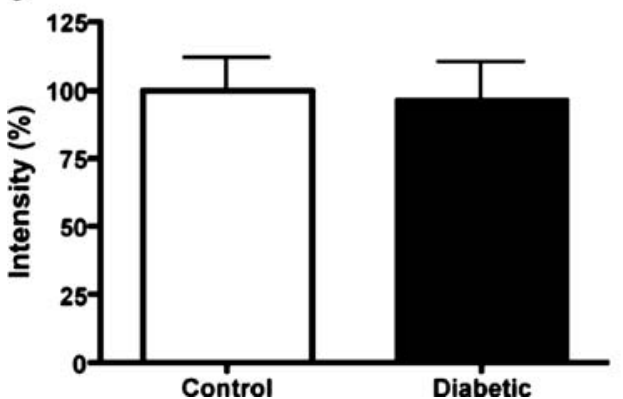

b

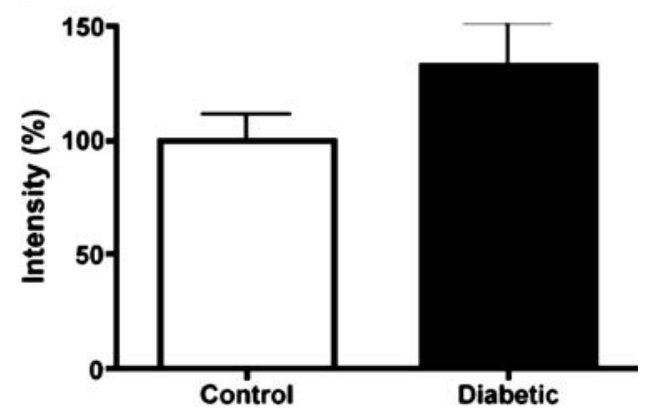

d

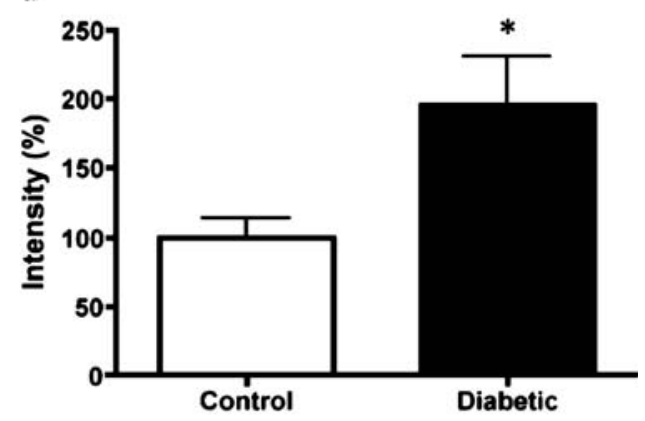

f

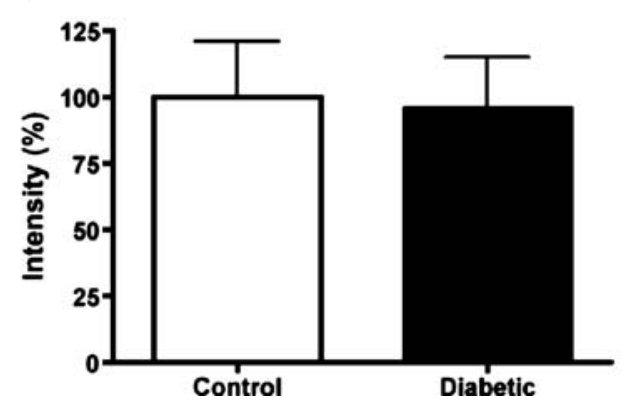

injection of nor-BNI alone. Morphine (15 mg/kg s.c.) was included as a positive control and also partially alleviated allodynia of diabetic rats $(\mathrm{AUC}=22.32 \pm 4.80)$, although mild and transient respiratory depression and sedation were noted at this dose and might have confounded interpretation of behavioural data.

Formalin hyperalgesia

Injection of $0.5 \%$ formalin solution into the hindpaw of control rats induced minimal flinching during both phase 1 $(4 \pm 2$, mean \pm SEM) and phase $2(6 \pm 2$; Fig. 7a). Vehicletreated diabetic rats exhibited increased flinching during both phase $1(12 \pm 7)$ and phase $2(96 \pm 8)$. Gabapentin $(50 \mathrm{mg} / \mathrm{kg}$ i.p.) was without effect on phase 1 flinching in diabetic rats $(14 \pm 4)$, but reduced $(p<0.01)$ phase 2 flinching $(23 \pm 5)$ compared with vehicle-treated diabetic rats. Similarly, asimadoline had no effect on phase 1 at any dose given to diabetic rats $(8 \pm 3,15 \pm 5$ and $17 \pm 4$ for 1,5 and $15 \mathrm{mg} / \mathrm{kg}$ s.c., respectively). However, phase 2 flinching in diabetic rats was significantly $(p<0.05)$ reduced by asima- doline at the $1 \mathrm{mg} / \mathrm{kg}(50 \pm 15)$ and $5 \mathrm{mg} / \mathrm{kg}(46 \pm 15)$, although it was without effect at the $15 \mathrm{mg} / \mathrm{kg}$ dose $(97 \pm 26)$ (Fig. 7a). Diabetic rats were also pre-treated with nor-BNI $30 \mathrm{~min}$ (intraplantar, i.p.) or $10 \mathrm{~min}$ (intrathecal) prior to asimadoline injection. Intraplantar injection of $100 \mu \mathrm{g}$ norBNI did not alter the action of asimadoline, whereas i.p. injection of nor-BNI (1 mg) or delivery of nor-BNI $(10 \mu \mathrm{g}$ in $10 \mu \mathrm{l})$ directly to the spinal cord significantly reduced the effect of asimadoline treatment (Fig. 7b).

\section{Discussion}

Dynorphin A is an endogenous opioid KOR ligand that shows increased levels in the spinal cord and sciatic nerve of rats following nerve injury and inflammation [9, 10]. In addition to opioid-associated antinociceptive properties, there is strong evidence that dynorphin also contributes to allodynia and hyperalgesia after nerve injury and helps sustain persistent neuropathic pain [11-23]. Intrathecal injection of dynorphin $\mathrm{A}$ induces prolonged tactile allody- 
Fig. 4 KOR immunoreactivity in satellite cells of DRG neurons $(\mathbf{a}, \mathbf{b})$ and in Schwann cells of sciatic nerve (c, d) from control $(\mathbf{a}, \mathbf{c})$ and diabetic $(\mathbf{b}, \mathbf{d})$ rats. Arrowhead, KOR staining in satellite cells of DRG neurons; arrow, KOR staining in

Schwann cells of sciatic nerve, evident as distinctive signet ring profiles around axons.

Bar $=40 \mu \mathrm{m}$. Inset (a), wide-field view of a DRG from a control rat immunostained for KOR. Bar $=200 \mu \mathrm{m}$. Inset $(\mathbf{b})$, specificity of immunostaining by omission of the primary antibody. Bar=40 $\mu \mathrm{m}$
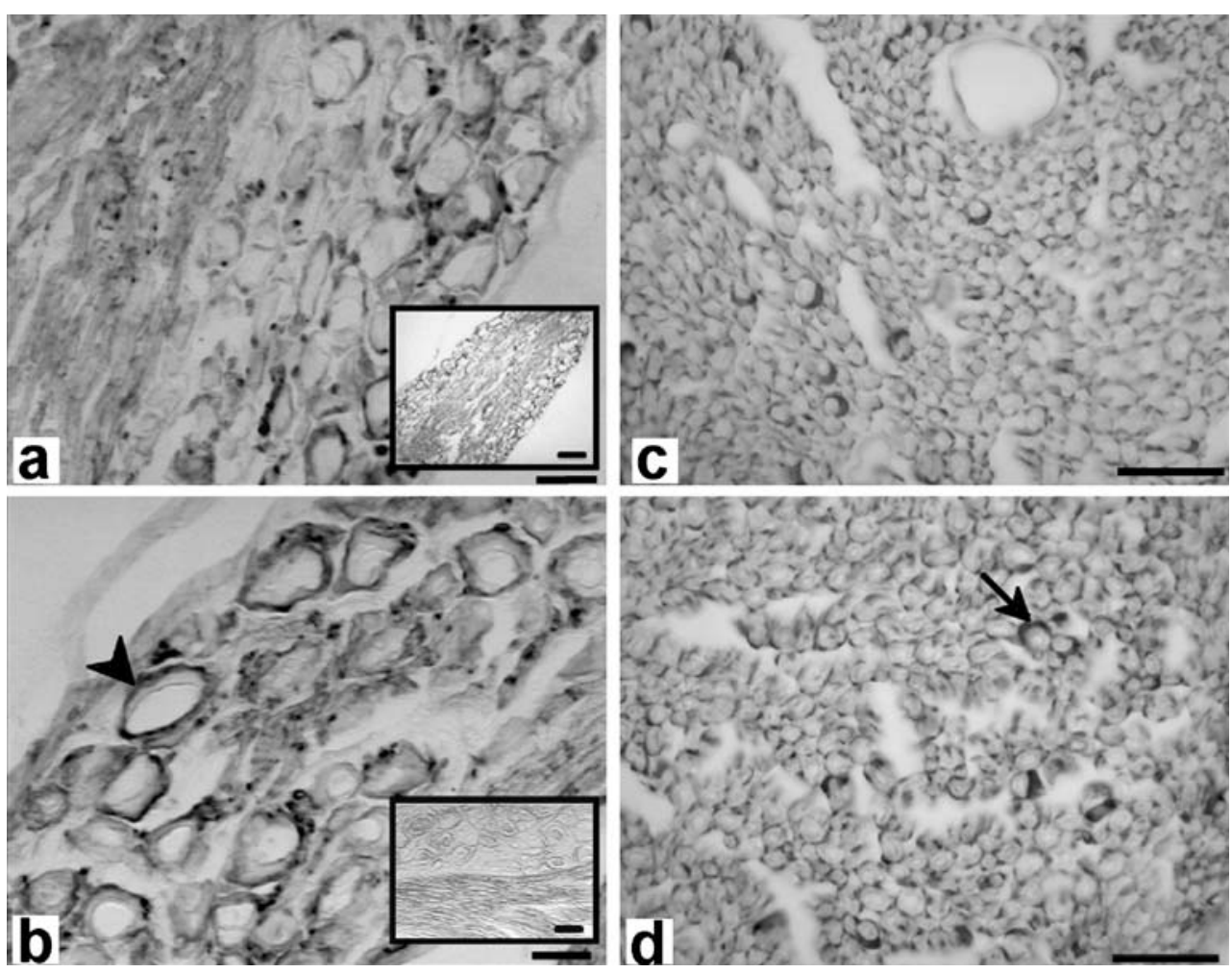

nia that is blocked by antagonists of NMDA, but not opioid receptors [7]. This switch from antinociceptive to pronociceptive properties may reflect initial activation of the KOR and then direct or indirect interactions with NMDA receptors at higher concentrations [13, 14, 24]. Caution must therefore be exercised when trying to correlate changes in tissue levels of the peptide with specific physiological properties.

Our detection of dynorphin A protein in the DRG, peripheral nerves and skin of control rats is consistent with a prior report of immunoreactivity for this protein colocalising with neuropeptides in primary afferents project-

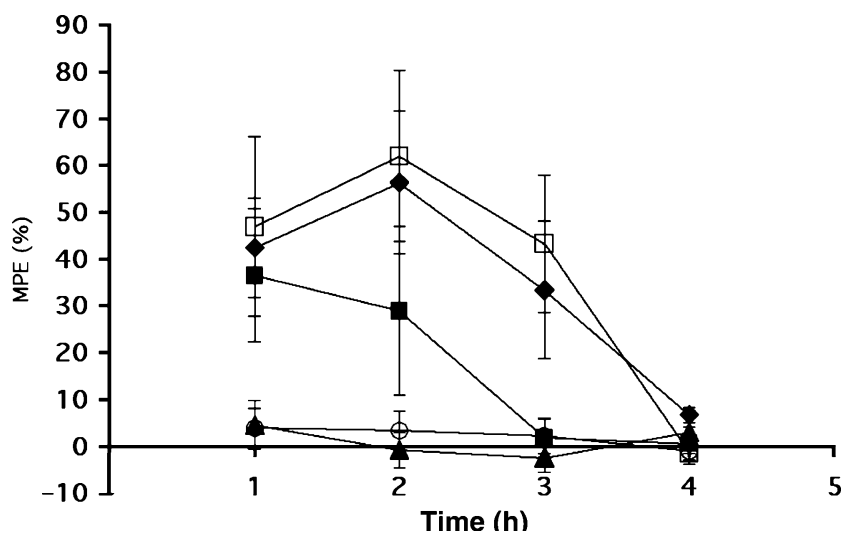

Fig. 5 Efficacy of systemic treatment with $1 \mathrm{ml} / \mathrm{kg}$ s.c. of $0.9 \%$ saline (open circles), $50 \mathrm{mg} / \mathrm{kg}$ i.p. gabapentin (open squares) or asimadoline at doses of 1 (closed triangles), 5 (closed squares) or 15 (closed diamonds) $\mathrm{mg} / \mathrm{kg}$ s.c. on tactile allodynia in diabetic rats. Data points are group mean \pm SEM of the percentage maximal effect (MPE) for each treatment. $n=8$ per group ing to the skin of guinea pigs [25]. Our immunolocalisation of dynorphin A to neuronal cell body cytoplasm confirms a neuronal distribution. However, we were surprised to find that the dominant immunostaining for dynorphin $\mathrm{A}$ in the sciatic nerve was not in axons but in Schwann cells, and possibly in other non-neuronal cells within the endoneurium. This need not exclude the presence of dynorphin A undergoing transport from neuronal cell bodies to the periphery by axonal transport, as it could be present at levels below our detection limits, but it does highlight an alternative site of dynorphin A protein in peripheral nerve, the function of which has yet to be explored.

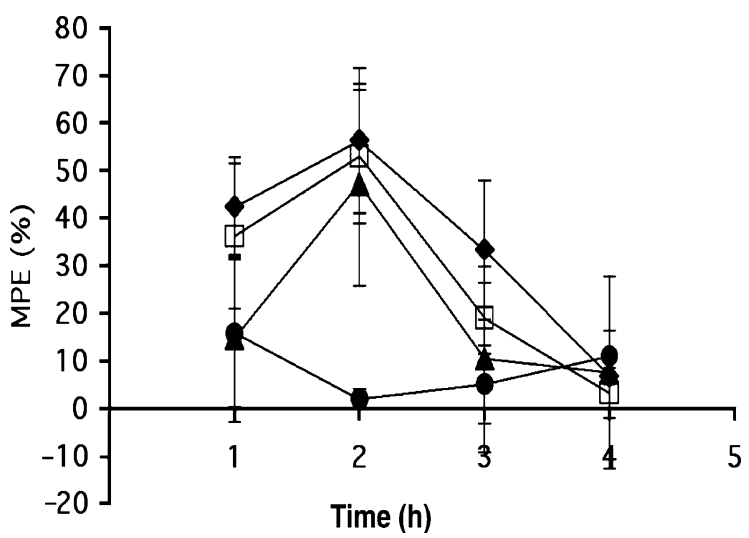

Fig. 6 Inhibition of the effect of asimadoline in diabetic rats by norBNI. Diabetic rats received either no pre-treatment (black diamonds), intraplantar saline (open squares) or nor-BNI by intraplantar (black circles) or i.p. (black triangles) injection $30 \mathrm{~min}$ before s.c. delivery of $15-\mathrm{mg} / \mathrm{kg}$ asimadoline. Data points are group mean \pm SEM of the percentage maximal effect (MPE) for each treatment. $n=8$ per group 
Table 1 Cumulative paw withdrawal threshold (quantified as AUC) over $4 \mathrm{~h}$ post-drug administration in control and diabetic rats

\begin{tabular}{lll}
\hline & Diabetic & Non-diabetic \\
\hline Saline & $15.6 \pm 2.0^{*}$ & $55.7 \pm 4.1$ \\
Asimadoline $15 \mathrm{mg} / \mathrm{kg}$ s.c. & $28.4 \pm 3.3$ & - \\
+ saline intraplantar & $29.5 \pm 4.2$ & $63.2 \pm 5.7$ \\
+ nor BNI i.p. $(1 \mathrm{mg})$ & $26.1 \pm 7.4$ & - \\
+ nor BNI intraplantar $(100 \mu \mathrm{g})$ & $10.5 \pm 0.8^{* *}$ & - \\
nor BNI intraplantar $(100 \mu \mathrm{g})$ & $17.8 \pm 2.5$ & $57.1 \pm 7.1$ \\
\hline
\end{tabular}

Data are mean \pm SEM

$*_{p}<0.05$,

$* * p<0.01$ vs asimadoline alone using the Kruskal-Wallis test followed by Dunn's post hoc test.

Diabetes did not change either the amount of dynorphin A protein or distribution of dynorphin A immunoreactivity in the DRG. In contrast, diabetes markedly increased dynorphin A protein levels in the sciatic nerve, its distal

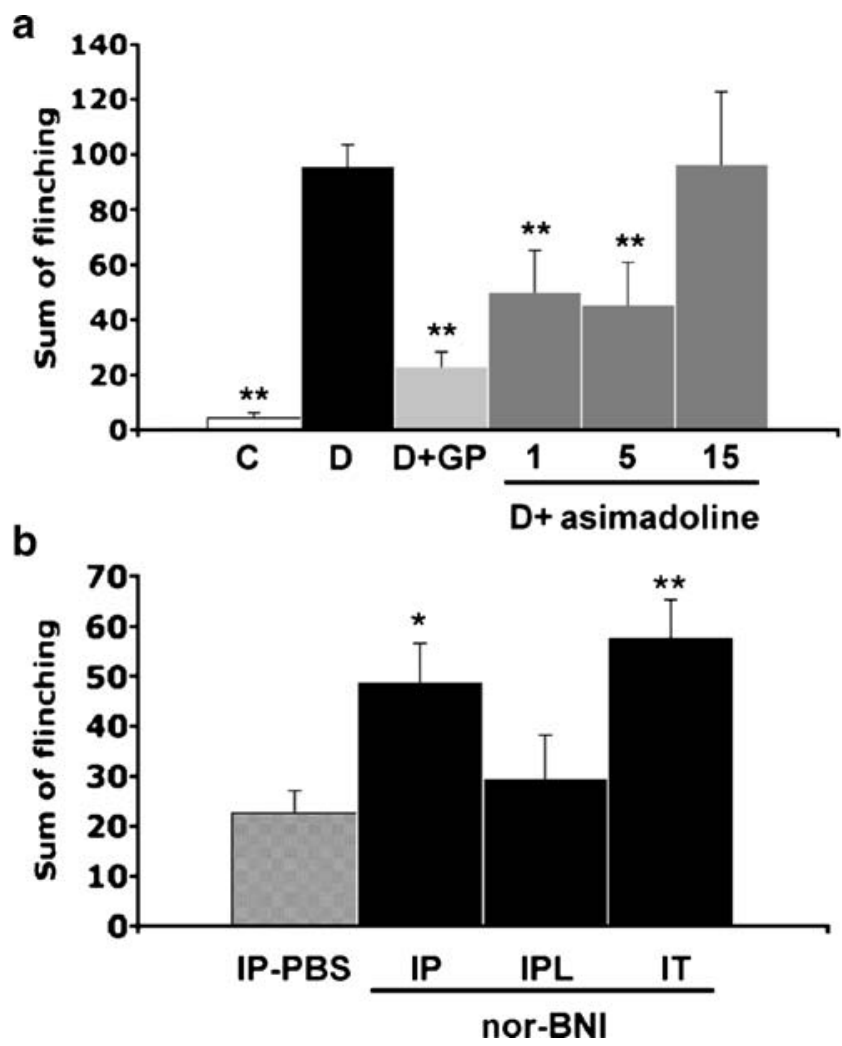

Fig. 7 a Sum flinches during phase 2 of the formalin test after asimadoline treatment. $C$ Control, $D$ diabetic, $D+G P$ diabetic $+50 \mathrm{mg}$ / $\mathrm{kg}$ i.p. gabapentin, 1 diabetic $+1 \mathrm{mg} / \mathrm{kg}$ s.c. asimadoline, 5 diabetic $+5 \mathrm{mg} / \mathrm{kg}$ s.c. asimadoline, 15 diabetic $+15 \mathrm{mg} / \mathrm{kg}$ s.c. asimadoline. Data are group mean \pm SEM. $n=5-6$ per group. ${ }^{* *} p<0.01$ vs diabetic group by one-way ANOVA followed by Dunnett's post hoc test. b Sum flinches during phase 2 of the formalin test after nor-BNI pretreatment. Diabetic rats were treated with $5 \mathrm{mg} / \mathrm{kg}$ s.c. asimadoline after pretreatment with PBS (IP-PBS), or nor-BNI by intraperitoneal (IP), intraplantar (IPL) or intrathecal (IT) injection. Data are group mean \pm SEM. $n=6-8$ per group. ${ }^{*} p<0.05, * * p<0.01$ vs IP-PBS group by one-way ANOVA followed by Dunnett's post hoc test tibial and peroneal branches and also in the plantar foot skin. Diabetes has previously been shown to increase brain dynorphin levels [15]. The increase in peripheral nerves but not the DRG could reflect efficient axonal transport of nascent dynorphin A from the neuronal cell body to the periphery. However, we did not detect dynorphin A in axons of diabetic rats and the cellular distribution remained restricted to non-neuronal cells. Schwann cells are the primary lesion site for many hyperglycaemia-induced nerve changes, as they contain aldose reductase [26] and it is plausible that increased dynorphin A production represents another intracellular response to increased flux through the polyol pathway, although we have yet to investigate this possibility. When considering the functional consequences of increased dynorphin A in peripheral nerve during diabetes, it is noteworthy that the increase was coincident with the presence of tactile allodynia and formalin-evoked hyperalgesia. There are other models of neuropathic and inflammatory pain that show both allodynia and increased dynorphin A, although the increase is usually described in the spinal cord [9-11], whereas in our diabetic rats the increase was restricted to the periphery. Thus, while it is tempting to speculate that the behavioural indices of neuropathic pain and increased peripheral nerve dynorphin are associated, this should be approached with caution for the reasons discussed above.

Because neuropathic pain induced by nerve injury is associated with increased spinal KOR [27] and the pronociceptive aspects of dynorphin activity are mediated via spinal NMDA receptors, we looked for parallels between the diabetic rat and other models of nerve injuryinduced neuropathic pain by measuring the amount of KOR and NMDA receptor protein in the spinal cord of diabetic rats. However, we found no change in levels of KOR or NMDA-R1 protein in the spinal cord of allodynic diabetic rats so that the allodynia of diabetic rats cannot be attributed to a simple upregulation of these receptors.

The increase of dynorphin A in peripheral nerve and skin of diabetic rats prompted us to examine KOR in the periphery. Opioid receptors are axonally transported by capsaicin-sensitive primary afferent neurons [28], but we found that the dominant KOR-immunoreactivity was seen in satellite cells of the DRG and in Schwann cells of the sciatic nerve. The association of KOR with peripheral glia has not to our knowledge been reported, although KOR has been localised to astrocytes in the central nervous system [29] and implicated in the microglial-mediated spinal sensitisation properties of dynorphin [30]. The increased KOR protein seen in the sciatic and peroneal nerves of diabetic rats was not associated with novel expression of KOR-immunoreactivity in other cell types within the nerve, although again we cannot rule out the possibility of an increased amount undergoing axonal transport, as occurs 
during inflammation $[10,31]$, but which is below the limits of detection with our immunocytochemical techniques. The absence of any concomitant increase in the distal tibial nerve is surprising and at present unexplainable, although the lack of increase is consistent with the matching lack of increase in plantar foot skin, this being an area innervated by the tibial nerve. The presence of the KOR in skin has previously been inferred from pharmacological studies involving local delivery of antagonists [32, 33], but its cellular location has yet to be described.

Exploiting the presence of KOR in the footpad skin and the increased levels in peripheral nerves, we tested the ability of asimadoline, a peripheral-acting selective KOR agonist $[34,35]$, to alleviate sensory dysfunction induced by diabetes. Established tactile allodynia in diabetic rats was dose-dependently ameliorated by systemic delivery of asimadoline with an efficacy profile similar to that of morphine and gabapentin. While asimadoline and related arylacetamide KOR agonists have been reported to exhibit other properties that could mediate antinociception, e.g. sodium channel inhibition [36], our finding that the antiallodynic actions of asimadoline were abolished by pretreatment with the KOR antagonist nor-BNI, strongly suggests that the effect of asimadoline on tactile allodynia in diabetic rats was mediated via KOR. The ability of norBNI to block the actions of asimadoline was most marked and persistent when it was delivered locally to the paw, suggesting that the anti-allodynic actions of asimadoline in diabetic rats were mediated via peripheral, rather than spinal KOR.

We extended our studies of the actions of asimadoline to a second index of sensory dysfunction in diabetic rats, namely the increased flinching response to paw formalin injection. This model allows evaluation of spinal sensitisation processes and is thus distinct from tests of acute thermal or mechanical nociception. Formalin-evoked hyperalgesia in diabetic rats shares some features with the allodynia present in diabetic animals. These features include prevention by insulin therapy [22] and alleviation by gabapentin $[37,38]$ or a prosaposin-derived peptide [39], but they differ in responsiveness to aldose reductase inhibition $[1,22]$. In the present study we found that phase 2 of formalin-evoked hyperalgesia in diabetic rats was alleviated by systemic asimadoline and this was partially blocked by systemic or intrathecal nor-BNI, indicating KOR involvement in the mechanism of action of asimadoline. In phase 2 of the formalin test minimal peripheral input is amplified by modified spinal sensory processing mechanisms [40]. It is interesting to note that the doseeffect curves for alleviation of formalin hyperalgesia and tactile allodynia were dissimilar. Asimadoline at $1 \mathrm{mg} / \mathrm{kg}$ was effective against formalin-evoked hyperalgesia during phase 2 of the test, but not against tactile allodynia. Conversely, the highest dose used $(15 \mathrm{mg} / \mathrm{kg})$ was effective against tactile allodynia, but efficacy against phase 2 of the formalin test was lost. A similar loss of efficacy of asimadoline in high doses has been previously reported in studies of paw pressure sensitivity in normal rats [16]. The different dose:effect curves of asimadoline against tactile allodynia and formalin-evoked hyperalgesia in diabetic rats could reflect different causes of the two disorders, as suggested by their differential sensitivity to aldose reductase inhibitors [22], and/or distinct sites of action of asimadoline. Indeed, and in contrast to tactile allodynia, intraplantar injection of the KOR antagonist nor-BNI did not block the action of asimadoline on formalin-evoked hyperalgesia. However, spinal delivery of nor-BNI was effective, suggesting that even limited penetration of asimadoline in the central nervous system $[16,41]$ could play a role in its capacity to ameliorate formalin-evoked hyperalgesia.

In neuropathic pain states, including diabetic neuropathic pain, mu opioid receptor agonists are widely regarded as having a limited therapeutic window and a number of studies in diabetic rodents have suggested that hyperglycaemia also causes relative insensitivity to opiates [42, 43]. This may be caused by differences in drug distribution and kinetics between control and diabetic rats that make direct comparisons of systemically delivered drug efficacy difficult to interpret [44], although recent reports indicate that diabetic rats also show impaired function of spinal mu opiate receptors [45]. There is emerging experimental evidence that delta and kappa opioid receptors can provide plausible alternative targets for alleviating painful diabetic neuropathy [46] and recent clinical trials with oxycodone, a mixed mu and kappa opioid receptor agonist [47, 48] also support this approach. Asimadoline may provide a local therapeutic approach to treating diabetic painful neuropathy that avoids the sedation and dysphoria occurring with KOR agonists that penetrate the central nervous system [49] and also avoids the respiratory depression and potential for abuse associated with mu opioid agonists [50].

Acknowledgements This study was supported by Merck (Darmstadt, Germany) and NIH award DK057629 to N. A. Calcutt. We wish to thank A. Mizisin for advice regarding the immunolocalisation studies.

Duality of interest N. A. Calcutt received support from Merck, Darmstadt, Germany. G. D. Bartoszyk is employed by Merck, Darmstadt, Germany. Asimadoline was developed by Merck, Darmstadt, Germany, and is now developed by Tioga Pharmaceuticals, in which Merck holds financial interests.

\section{References}

1. Calcutt NA (2002) Potential mechanisms of neuropathic pain in diabetes. Int Rev Neurobio 50:205-228

2. Calcutt NA, Campana WM, Eskeland NL et al (1999) Prosaposin gene expression and the efficacy of a prosaposin-derived peptide 
in preventing structural and functional disorders of peripheral nerve in diabetic rats. J Neuropathol Exp Neurol 58:628-636

3. Freshwater JD, Svensson CI, Malmberg AB, Calcutt NA (2002) Elevated spinal cyclooxygenase and prostaglandin release during hyperalgesia in diabetic rats. Diabetes 51:2249-2255

4. Calcutt NA, Chaplan SR (1997) Spinal pharmacology of tactile allodynia in diabetic rats. Br J Pharmacol 122:1478-1482

5. Chavkin C, James IF, Goldstein A (1982) Dynorphin is a specific endogenous ligand of the kappa opioid receptor. Science 215:413-415

6. Faden AI, Jacobs TP (1984) Dynorphin-related peptides cause motor dysfunction in the rat through a non-opiate action. $\mathrm{Br} \mathrm{J}$ Pharmacol 81:271-276

7. Vanderah TW, Laughlin T, Lashbrook JM et al (1996) Single intrathecal injections of dynorphin A or des-Tyr-dynorphins produce long-lasting allodynia in rats: blockade by MK- 801 but not naloxone. Pain 68:275-281

8. Cho HJ, Basbaum AI (1988) Increased staining of immunoreactive dynorphin cell bodies in the deafferented spinal cord of the rat. Neurosci Lett 84:125-130

9. Draisci G, Kajander KC, Dubner R, Bennett GJ, Iadarola MJ (1991) Up-regulation of opioid gene expression in spinal cord evoked by experimental nerve injuries and inflammation. Brain Res 560:186-192

10. Hassan AH, Pzewlocki R, Herz A, Stein C (1992) Dynorphin, a preferential ligand for kappa-opioid receptors, is present in nerve fibers and immune cells within inflamed tissue of the rat. Neurosci Lett 140:85-88

11. Malan TP, Ossipov MH, Gardell LR et al (2000) Extraterritorial neuropathic pain correlates with multisegmental elevation of spinal dynorphin in nerve-injured rats. Pain 86:185-194

12. Wang Z, Gardell LR, Ossipov MH et al (2001) Pronociceptive actions of dynorphin maintain chronic neuropathic pain. J Neurosci 21:1779-1786

13. Lai J, Ossipov MH, Vanderah TW, Malan TP Jr, Porreca F (2001) Neuropathic pain: the paradox of dynorphin. Mol Interv 1:160-167

14. Laughlin TM, Larson AA, Wilcox GL (2001) Mechanisms of induction of persistent nociception by dynorphin. J Pharmacol Exp Ther 299:6-11

15. Berman Y, Devi L, Carr KD (1995) Effects of streptozotocininduced diabetes on prodynorphin-derived peptides in rat brain regions. Brain Res 685:129-134

16. Barber A, Bartoszyk GD, Bender HM et al (1994) A pharmacological profile of the novel, peripherally-selective kappa-opioid receptor agonist, EMD 61753. Br J Pharmacol 113:1317-1327

17. Binder W, Walker JS (1998) Effect of the peripherally selective kappa-opioid agonist, asimadoline, on adjuvant arthritis. $\mathrm{Br} \mathrm{J}$ Pharmacol 124:647-654

18. Binder W, Scott C, Walker JS (1999) Involvement of substance P in the anti-inflammatory effects of the peripherally selective kappa-opioid asimadoline and the NK1 antagonist GR205171. Eur J Neurosci 11:2065-2072

19. Machelska H, Pfluger M, Weber W et al (1999) Peripheral effects of the kappa-opioid agonist EMD 61753 on pain and inflammation in rats and humans. J Pharmacol Exp Ther 290:354-361

20. Walker J, Catheline G, Guilbaud G, Kayser V (1999) Lack of cross-tolerance between the antinociceptive effects of systemic morphine and asimadoline, a peripherally-selective kappa-opioid agonist, in CCI-neuropathic rats. Pain 83:509-516

21. Chaplan SR, Bach FW, Pogrel JW, Chung JM, Yaksh TL (1994) Quantitative assessment of tactile allodynia in the rat paw. J Neurosci Methods 53:55-63

22. Calcutt NA, Jorge MC, Yaksh TL, Chaplan SR (1996) Tactile allodynia and formalin hyperalgesia in streptozotocin-diabetic rats: effects of insulin, aldose reductase inhibition and lidocaine. Pain 68:293-299
23. Gardell LR, Ibrahim M, Wang R et al (2004) Mouse strains that lack spinal dynorphin upregulation after peripheral nerve injury do not develop neuropathic pain. Neuroscience 123:43-52

24. Bakshi R, Ni RX, Faden AI (1992) N-methyl-D-aspartate (NMDA) and opioid receptors mediate dynorphin-induced spinal cord injury: behavioral and histological studies. Brain Res 580:255-264

25. Gibbins IL, Furness JB, Costa M (1987) Pathway-specific patterns of the co-existence of substance $\mathrm{P}$, calcitonin gene-related peptide, cholecystokinin and dynorphin in neurons of the dorsal root ganglia of the guinea-pig. Cell Tissue Res 248:417-437

26. Powell HC, Garrett RS, Kador PF, Mizisin AP (1991) Finestructural localization of aldose reductase and ouabain-sensitive, $\mathrm{K}(+)$-dependent p-nitro-phenylphosphatase in rat peripheral nerve. Acta Neuropathol 81:529-539

27. Xu M, Petraschka M, McLaughlin JP et al (2004) Neuropathic pain activates the endogenous kappa opioid system in mouse spinal cord and induces opioid receptor tolerance. J Neurosci 24:4576-4584

28. Laduron PM (1984) Axonal transport of opiate receptors in capsaicin-sensitive neurones. Brain Res 294:157-160

29. Bunn SJ, Hanley MR, Wilkin GP (1985) Evidence for a kappaopioid receptor on pituitary astrocytes: an autoradiographic study. Neurosci Lett 55:317-323

30. Svensson CI, Hua XY, Powell HC, Lai J, Porreca F, Yaksh TL (2005) Prostaglandin E2 release evoked by intrathecal dynorphin is dependent on spinal p38 mitogen activated protein kinase. Neuropeptides 39:485-494

31. Hassan AH, Ableitner A, Stein C, Herz A (1993) Inflammation of the rat paw enhances axonal transport of opioid receptors in the sciatic nerve and increases their density in the inflamed tissue. Neuroscience 55:185-195

32. Abbott FV (1988) Peripheral and central antinociceptive actions of ethylketocyclazocine in the formalin test. Eur $\mathrm{J}$ Pharmacol 152:93-100

33. Haley J, Ketchum S, Dickenson A (1990) Peripheral kappa-opioid modulation of the formalin response: an electrophysiological study in the rat. Eur J Pharmacol 191:437-446

34. Barber A, Gottschlich R (1992) Opioid agonists and antagonists: an evaluation of their peripheral actions in inflammation. Med Res Rev 12:525-562

35. Barber A, Bartoszyk GD, Greiner HE et al (1994) Central and peripheral actions of the novel kappa-opioid receptor agonist, EMD 60400. Br J Pharmacol 111:843-851

36. Joshi SK, Lamb K, Bielefeldt K, Gebhart GF (2003) Arylacetamide kappa-opioid receptor agonists produce a tonic- and usedependent block of tetrodotoxin-sensitive and -resistant sodium currents in colon sensory neurons. J Pharmacol Exp Ther 307:367-372

37. Cesena RM, Calcutt NA (1999) Gabapentin prevents hyperalgesia during the formalin test in diabetic rats. Neurosci Lett 262:101-104

38. Field MJ, McCleary S, Hughes J, Singh L (1999) Gabapentin and pregabalin, but not morphine and amitriptyline, block both static and dynamic components of mechanical allodynia induced by streptozocin in the rat. Pain 80:391-398

39. Calcutt NA, Freshwater JD, O'Brien JS (2000) Protection of sensory function and antihyperalgesic properties of a prosaposinderived peptide in diabetic rats. Anesthesiology 93:1271-1278

40. Yaksh TL (1999) Spinal systems and pain processing: development of novel analgesic drugs with mechanistically defined models. Trends Pharmacol Sci 20:329-337

41. Jonker JW, Wagenaar E, van Deemter L et al (1999) Role of blood-brain barrier P-glycoprotein in limiting brain accumulation and sedative side-effects of asimadoline, a peripherally acting analgesic drug. Br J Pharmacol 127:43-50 
42. Raz I, Hasdai D, Seltzer Z, Melmed RN (1988) Effect of hyperglycemia on pain perception and on efficacy of morphine analgesia in rats. Diabetes 37:1253-1259

43. Malcangio M, Tomlinson DR (1988) A pharmacologic analysis of mechanical hyperalgesia in streptozotocin/diabetic rats. Pain $76: 151-157$

44. Courteix C, Bourget P, Caussade F et al (1998) Is the reduced efficacy of morphine in diabetic rats caused by alterations of opiate receptors or of morphine pharmacokinetics? J Pharmacol Exp Ther 285:63-70

45. Chen SR, Pan HL (2003) Antinociceptive effect of morphine, but not mu opioid receptor number, is attenuated in the spinal cord of diabetic rats. Anesthesiology 99:1409-1414
46. Suzuki Y, Goto K, Shiizaki K et al (2001) Antinociceptive effect of U-50488H, a kappa-opioid agonist, in streptozotocin-induced diabetic mice. J Pharm Pharmacol 53:521-526

47. Gimbel JS, Richards P, Portenoy RK (2003) Controlled-release oxycodone for pain in diabetic neuropathy: a randomized controlled trial. Neurology 60:927-934

48. Watson CPN, Moulin D, Watt-Watson, Gordon A, Eisenhoffer J (2003) Controlled-release oxycodone relieves neuropathic pain: a randomized controlled trial in painful diabetic neuropathy. Pain 105:71-78

49. Pfeiffer A, Brantl V, Herz A, Emrich HM (1986) Psychotomimesis mediated by kappa opiate receptors. Science 233:774-776

50. Horwell DC (1988) Kappa opioid analgesics. Drug Future 13:1061-1070 